\title{
Using Traditional / ICT Tools While Teaching Translation to Opera Singers
}

\author{
Kateřina Štroblová* \\ Institute of Applied Language Studies, University of West Bohemia, Pilsen, 306 14, Czech Republic \\ *Corresponding author: stroblov@ujp.zcu.cz \\ Received December 03, 2014; Revised December 19, 2014; Accepted December 28, 2014
}

\begin{abstract}
Translation is a type of activity seldom proposed by modern teaching materials which emphasize communicative methods. Yet the needs of opera singers studying Italian as a foreign language differ completely from those of students' studying Italian for other purposes and must indeed include translation. The process of teaching how to translate opera is influenced by several factors; both linguistic and extralinguistic aspects, such as the quality of used scores or musical texts, specific vocabulary, poetic word order, as well as the specific curriculum and the accessibility of didactic tools, influence the process. The aim of this paper is to summarize the research which has been conducted by the author with the aim of finding out the advantages and disadvantages of using traditional and ICT tools for musical text translation. Comparing both types of tools, examples of their use are given. In accordance with the hypothesis, some of the tools are found to be completely unsuitable for such specific translations. Although it is not obvious at first, the results of this research suggest that in order to become an autonomous user of any kind of tool it is essential to learn how to use it without regard to the type of tool. These results are of significance for teachers and students alike. Finally, the paper suggests that further research into tools used for musical text translation is needed.
\end{abstract}

Keywords: translation, traditional tools, ICT tools, teaching process, opera singers, musical texts

Cite This Article: Kateřina Štroblová, "Using Traditional / ICT Tools While Teaching Translation to Opera Singers." American Journal of Educational Research, vol. 2, no. 12 (2014): 1277-1283. doi: 10.12691/education2-12-23.

\section{Introduction}

Modern didactics of foreign languages, including that of Italian, emphasize the communicative method which normally eliminates or minimizes the use of translationbased activities. Even grammar theory and lexicology are dealt with entirely in Italian by lots of Italian teaching materials. Recently the larger Italian, as well as foreign publishing houses, are moving to technologically innovative methods which are transforming or supplementing traditional teaching materials with new tools such as interactive software to be used autonomously or directly in the classrooms (LIM - Lavagna interattiva multimediale). There are also new online platforms for sharing ideas directly in the target language with teachers and students worldwide. All these possibilities are compatible with the communicative approach of foreign language didactics.

The needs of opera singers studying Italian as a foreign language differ completely from those who are studying Italian for communicative purposes. The opera singer basically needs to learn the correct pronunciation of Italian texts and to be able to interpret them correctly, in accordance with the sung scores. Teaching Italian to opera singers must indeed include translation.
There is not enough research done on specific topics such as teaching translation to opera singers. On the one hand, lots of theoretical works on translation dedicate only a little bit of attention to the translation of musical texts, e.g. [1], more attention is paid to poetic translation, e.g. $[2,3]$ which does not correspond completely to opera singers' needs. On the other hand there are plenty of works and research focused on didactics of which only a limited part deals with the didactics of translation. The author of the present paper was hitherto unable to find any specific material or research closely related to teaching translation to opera singers. There are excellent analyses of Italian musical and opera texts, provided by a Czech translator, in didactic materials intended for students of conservatories and musical academies in the Czech Republic $[4,5]$. This translator, herself a teacher at the Conservatory of Prague, translated tens of opera pieces into Czech and collaborates with Czech theaters in the capital and in regional centers, yet promotes the use of translations already made by professionals among opera singers. Finally, in Italy an important research dedicated to musical lexicology (LesMu - Lessicologia musicale) is conducted [6] but it differs completely from the topic of this research which is focused on the teaching process, not on terminology.

This paper presents the results of a research conducted at the Conservatory of Pilsen, in the Czech Republic, where opera singers are taught Italian. The principal aim 
of the research was to find the advantages and disadvantages of traditional and ICT tools used for musical texts translation. The research, however, was more complex; showing different aspects related to the teaching process and translation. It can be divided into three parts.

The research's first aim was to compare two different teaching approaches in order to find out how using translation activities in the teaching process correspond to translation ability. Hypothetically, the introduction of ICT tools should facilitate students in their translations.

The research's second goal was to compare the difficulties that students encounter while translating autonomously with the difficulties they encounter when the translations are made in the classroom. The hypothesis was that the difficulties depend closely on the used tools.

The final issue at hand was the comparison of traditional and ICT tools used for translation of opera scores, in accordance with the hypothesis that some of the tools are completely unsuitable for such specific translations.

For the purposes of this research, traditional tools are defined as a blackboard, cassette/cd player, printed teaching materials accompanied by audio-CDs and a paper dictionary, while the interactive board with connection to internet, textbook and exercise-book accompanied by interactive software and electronic dictionaries are considered to be ICT tools. The materials are described subsequently in detail.

\section{Materials and Methods}

For the presented research that covers a period of twelve years, from September 2002 to September 2014, opera singers were taught Italian in small groups where the average number of students was 6 per group. Each group was taught systematically for four years at the above-named institution. The participants in the research were both regular and distance students-for whom Italian language was obligatory. The total number of these students between 2002 and 2014 was 103. Of those, 73 students were regular students and 30 were distant students. The curriculum of the distant students in Italian language covered the same amount of knowledge of the regular students. As the conservatory is a school accessible for talented students with no age limit, the regular students aged 18 on average (standard deviation 3) and the distance students aged 26 on average (standard deviation 10) at the beginning of teaching process.

The research is based partially on the observation of all 103 students while teaching translation, on the analysis of musical texts translated during the twelve year period and on the analysis of a questionnaire distributed among the current students in September 2014.

Traditional tools were used from the beginning of the research in 2002. The classroom was equipped with a traditional blackboard and a cassette/cd player. The principal teaching material was a Czech textbook supplemented by an audio-CD [7]. This textbook widely explains every grammatical aspect in its 35 chapters, providing a series of examples supplemented with Czech translation, starting at an absolutely elementary level and progressing towards complex grammatical structures, except the historical grammar forms. The broad range of lexicon is summarized in an Italian-Czech vocabulary at the end of the book (three thousand five-hundred of the most frequent headwords). The texts are used to promote the topics and singular chapters for the most part do not have a dialogical character and can be considered very detached from real life. Also, the recordings are only read versions of the same texts with no regard to authentic local pronunciations or real situations. From the graphic point of view, the book is very simple; mostly colorless and equipped only with few black and white images. From chapter 11 onwards the book presents authentic reading texts (extracted from literary works, newspapers or journal articles). The exercises, besides traditional drill type, are also translation exercises both from Italian to Czech as well as from Czech to Italian. The most interesting part of the majority of chapters from the translatological point of view is even called "Problemi di traduzione" (Problems of translation). It is a space dedicated to particular Italian words and their translation into Czech in different contexts, or to Czech words which can be translated in Italian in varied manners.

This traditional book is not a specific textbook intended for opera singers and gives no idea about poetic translation, archaic vocabulary, historical grammar forms or orthographical difficulties that a student may come across while translating the scores. This book, originally published in 1985, was used by several Czech generations in all types of schools, including Czech universities, and is still the main textbook of many Italian courses, especially in Czech conservatories.

The above mentioned textbook was supplemented while teaching translation with the only Czech materials intended specifically for opera singers published initially by the author, Marie Kronbergerová, [4] in 1996, and afterwards by the Czech Academy of music [5] in 2009. In both cases, the materials show the typical character of Czech university textbooks with no images and no recordings. These materials cover the main vocal texts that opera singers study in the first years (Niccolò Vaccai: Metodo pratico di canto italiano, Arie antiche) and some opera arias. The arias have been modified by adding punctuation and the capitals at the beginning of verses were removed. Where it was possible, the wider context and information about composers, librettists and operas are also given. All the musical texts are equipped with a word-by-word translation into Czech, sometimes completed by partial poetic translation. The poetic and archaic lexicon is explained, as well as the obsolete grammar forms and orthographical specifics and exercises of phonetical and grammatical aspects are given. The biggest disadvantage of the recent material [5] is the absence of translation activities. In the previous textbook [4], exercises for translation activities made up part of the studied text. Neither of the mentioned materials includes a specific vocabulary part.

Traditional paper dictionaries must be acknowledged as part of the traditional tools for teaching translation. The bilingual alphabetical Italian-Czech dictionary, containing approximately thirty thousand headwords and also poetic terms, published originally in the 1956 and its later versions were used at the Conservatory of Pilsen [8]. The dictionary is not available in electronic version and searching for an item in it is very slow. The translation 
activities were very time-consuming and only a little space was dedicated to conversation or other communicative activities till 2010.

From 2010 onwards modern technologies entered the conservatory. The classroom was equipped with a computer with internet connection and an interactive board. The teachers were trained to use the new tools including the software and were engaged in the national project whose outputs were new digital teaching materials. The school curriculum also changed.

The main textbook was replaced by monolingual teaching materials $[9,10,11,12]$ offering interactive software for individual work and for the interactive board (LIM). These new tools are graphically very attractive, have audio and video components and allow the teacher to create her/his own interactive teaching materials. The grammar is explained in target language and only some examples with no translation are given. The textbooks and the exercise-books do not offer any bilingual vocabulary. Recently there is a possibility to download Italian-Czech vocabulary related to 11 units of the book from the publisher's website. The grammar covered by the book is not very advanced and in four years of study does not cover more complex forms; the vocabulary and phraseology are focused on daily situations, the texts have mainly dialogical character and lots of prompts for stimulating communication. The translation activities disappeared completely from teaching materials.

Musical texts could be widely introduced in the classroom due to the internet connection. Popular songs as well as opera pieces can be watched and listened to directly in the classroom. For purposes of translation, online applications can be used. Students are allowed to use their phones for translation activities during the lessons. Searching for words has become a much faster process.

In both cases, from 2002 till 2010 (13 groups) and from 2010 till 2014 (5 groups), the teaching process was regularly enriched by other materials, especially by songs for children [13], popular songs [14] and other songs and opera texts selected and analyzed by the teacher.

In September 2014 the current students of Italian at the Conservatory of Pilsen were given a questionnaire divided into three parts. The first part of the questionnaire was focused on finding a preferred method for testing vocabulary. The respondents were asked to rank 11 different methods of testing. The second part of the questionnaire was focused on finding the major difficulties related to translations. The respondents were given 7 options with concrete examples and were asked to specify the frequency of their occurrence on a scale from always to never. The last part of the questionnaire was focused on the character of tools used while translating from Italian. The questionnaire was filled anonymously during class time by 20 of current students who are not complete beginners and have already gained some experience in translation.

\section{Results and Discussion}

The results of the research, as well as the research questions and the analysis obtained by observation and by the questionnaire can be divided into three parts.

\subsection{Translation in the Teaching Process}

The first part of the research unveiled the advantages and disadvantages of two different teaching processes; one based on use of traditional tools, the other based on use of ICT tools as described above. The given statements are based on the comparison of the teaching processes and the translation ability acquired by the observed students as assessed by the teacher and the feeling which students continually reported during classes.

\subsubsection{Traditional Tools in the Teaching Process}

The advantages of the combination of all the traditional tools mentioned above regarding the specific needs of translation of musical texts can be summarized as follows:

- deep knowledge of grammar structures, including historical grammatical constructs

- wide knowledge of lexicon, including poetic and archaic forms

- lots of musical texts

- lots of translation activities

- tool for searching poetic vocabulary

- all the materials available in the student's native tongue

The disadvantages of the combination of all the traditional tools mentioned above as reflected by the specific needs of translation of musical texts can be summarized as follows:

- no interactivity

- no graphic attractiveness

- few recordings

- no specific opera dictionary

- searching activities very slow

After four years of studies, the most active and motivated students from the 12 observed groups supported by traditional teaching process and traditional tools were able to translate unknown texts autonomously with few major inaccuracies and some minor inaccuracies.

\subsubsection{ICT Tools in the Teaching Process}

The advantages of the combination of all the ICT tools mentioned above as far as the specific needs of translation of musical texts is concerned can be summarized as follows:

- interactivity

- graphic attractiveness

- lots of audio and video recordings

- searching activities very fast

The disadvantages of the combination of all the ICT tools mentioned above regarding the specific needs of translation of musical texts can be summarized as follows:

- superficial knowledge of grammar structures, not including the historical forms

- limited knowledge of lexicon, not including the poetic and archaic forms

- no specific opera dictionary

- few translation activities

- no tool for searching poetic vocabulary

- no materials in native tongue

After four years of studies, students from 5 observed groups supported by ICT tools and taught primary using a communicative method reported not being able to translate without big difficulties. This fact was also 
attested to in the teacher's assessment of their translations. Not even texts with low orthographical specifics and without historical grammatical forms. Only the most active and motivated students were able to translate autonomously with lots of major inaccuracies.

Contrarily to the hypothesis, the introduction of ICT tools itself does not facilitate translation activities as this introduction is accompanied by the repression of translation activities.

In any case, translation activities have not disappeared completely from the teaching process for two reasons: students continue to ask the teacher to help them with translations of the interpreted scores; the learning process for many of them is still connected with translations in their native tongue. This statement is supported by the results of the first part of the questionnaire.

\subsubsection{Research on Testing Vocabulary}

The order of 11 different methods of testing (as expressed by the average position assigned to them by the students) gave the following result:

1. matching Italian words to Czech ones (2.1)

2. matching Italian words to images (4)

3. translating Italian words to Czech (5.1)

4. translating Czech words to Italian (5.4)

5. matching logical pairs of words in Italian (5.5)

6. giving Italian names to images (5.9)

7. excluding the alien Italian word from a group (6.1)

8. selection of paired words from a group of Italian words (7.2)

9. selection of word to complete an Italian sentence (7.4)

10. matching Italian word to definition (7.7)

11. matching Italian words to gaps in Italian text (9.6)

As can be observed, the preferred method was that in which the students were engaged in passive translation. The five most preferred methods involved testing isolated words, either in relation to their meaning in Czech, or at the very least expressed by an image. Testing with no relevance to the students' mother tongue occupied the middle positions and testing based on larger context is definitely at the bottom of the preferences. The testing preferences reflect the learning approach of the tested students who prefer memorizing isolated words to context related learning.

\subsection{Translation Difficulties in the Teaching Process}

The process of teaching how to translate opera is influenced by several factors, linguistic and extralinguistic. The second part of the research revealed whether the difficulties recognized by the analysis of translations made in the classroom and the difficulties faced by the students when translating autonomously depend on the used tools.

\subsubsection{Analysis of Translation Difficulties}

The analysis of the text and of student translations made over the course of twelve years shed light on the linguistic factors influencing classroom translations. Those can be defined as:

1. quality of musical text

2. orthographical specifics of musical text

3. grammatical specifics of musical text

4. specific vocabulary of musical text
5. poetic word order of musical text

The quality of musical texts influences the translation process fundamentally. While translating a popular song is usually facilitated by the accessibility of the correct version of the original text, the student translating opera scores may encounter several difficulties such as unreadable score or transcription. The scores, which are not so easily found on the Internet, can even contain linguistic mistakes. They often do not include punctuation and sometimes even the spaces between the words or their syllable (commonly expressed by a hyphen) are missing.

The orthographical aspect of the translated musical text is of great importance as well. Speaking of opera singers' repertoire, even if limited by Italian production, several geographical and historical aspects must be taken into account. Italian, as all the modern languages, is a dynamic structure and its local and temporary appearance can differ a lot. Because of this the translated musical texts, especially the opera scores, present a wide range of orthographical specific, such as different transcriptions of the same word and very frequently, contracted forms.

Historical grammatical forms, which not only differ from modern grammar and lexicology rules but can even go against them, complicate the translation. The teaching process in this case must be widened in comparison to the teaching of modern language use.

Lexicography is a very important aspect of musical text translation. The vocabulary of the opera scores is really a specific theme which is to be taught in addition, or sometimes in comparison, to a common vocabulary. The lexicon is not only poetic but frequently archaic including typical poetic figures such as metaphor, synecdoche etc. For this reason the use of current language knowledge is not sufficient in decoding the content of the translated message, sometimes even the modern meaning of a term may be confusing.

Another topic explicitly related to any kind of poetic text is that of word order. If there is a need to teach the poetic and archaic vocabulary in addition to modern terms, teaching the Italian word order must be included in the curriculum starting at the beginner's level in order to prepare students for essential parsing activities.

\subsubsection{Research of Translation Difficulties}

The difficulties indicated by the respondents of the questionnaire (expressed by the number of frequency on a scale of 'always-often-sometimes') can be subsequently listed from the most to least frequent as follows:

1. The translation of isolated words is comprehensible but the whole sentence/text is not (e.g. caro mio ben). 5-6-2

2. The meaning of the translated word does not facilitate the translation (e.g. preposition). 3-6-4

3 . The word cannot be translated because it is not in its elementary form (e.g. vado). 2-7-11

4. The word cannot be translated because it is contracted (e.g. m'). 2-6-7

5 . The word cannot be translated because the part of speech cannot be determined (e.g. legge). 1-6-6

6 . The correct meaning of a translated word cannot be selected from present options (e.g. casa). 1-6-2

7. The searched word is not present in the dictionary (e.g. archaic expression). 1-6-2 
These results, when compared with the analysis of difficulties, help us understand whether translations are dependent on the tools being used. The most pressing problems indicated by the students are related to lack of translation experience and to the specific requirements of poetic translation, which requires much more interpretative activity than word-by-word translation. The third most frequent difficulty shows a lack of deep knowledge of grammar to be a problem, as only the elementary forms can be found in most of the types of dictionaries. The fourth difficulty is closely related to orthographical and grammatical knowledge. The fifth difficulty is sometimes related to grammatical knowledge but may be influenced by word order too. The sixth difficulty is closely related to the target language but may also concern the type of dictionary, as the modern applications often do not offer larger context. The least frequent difficulty demonstrates that there is no very frequent difficulty in finding a word in a dictionary.

This result refutes the hypothesis, as the most frequent difficulties do not relate to the tools used but to translating competence.

\subsection{Translation Tools in the Teaching Process}

The third part of the research focused on a comparison of translation tools and was aimed at finding whether some of the used tools are completely unsuitable for translation of musical texts.

\subsubsection{Research on Translation Tools}

When asked about the tools used for translations, 90\% of the 20 respondents of the questionnaire indicated online applications, easily accessible from a computer or phones, to translate from Italian directly to Czech. For 85\% of them the most frequently used application is Google [15], $55 \%$ of them also uses online Italian-Czech dictionary [16]. Exactly 50\% combines the use of internet and traditional paper dictionaries. Only $10 \%$ use an electronic dictionary which must be installed on a PC. $90 \%$ of the respondents also mentioned the teacher as a tool used for translations.

\subsubsection{Experiment on Translation by Traditional and ICT Tools}

During the twelve year period of translation activities conducted at the Conservatory of Pilsen, the author of this text realized, through the translation and analysis of numerous musical texts, that certain tools, currently used and available, are more suitable for the purpose of opera text translation than others. Comparing several texts which have been translated using both traditional and ICT tools, one can conclude based on the tools most frequently used by students which tools are more suitable for this very specific purpose. As a model for the present research the following experiment was conducted: one quatrain of Alessandro Scarlatti (1659 - 1725) was translated by Google Translator as a complex text, by Italian-Czech online dictionary and by traditional paper Italian-Czech dictionary.

After the first attempt by Google Translator in the original quatrain the contracted forms “m’impiaga” and "m'incende" were substituted by full forms so the original and the English and Czech versions are the following:

Più mi impiaga quel occhio nero,

Più mi incende quel bianco sen;

E trafitto dal nume arciero,

Io mi sento venir meno.

The more I impiaga those eyes black,

More incende me that white sen;

It pierced the archer god,

I feel faint.

Čím víc jsem impiaga ty oči černé,

Více incende mi, že bílý sen;

To probodl boha lukostřelec,

Cítím se na omdlení.

Comparing the Czech and the English versions, it is evident that the translator actually passes the words through an English database while translating from Italian to Czech. This is the only explanation for some of the word choices, for example "quel" translated correctly in the first verse in both languages but changing the part of speech from English to Czech interpreting "that" as a conjunction instead of a pronoun in the second verse. Other aspects can be observed: the verbs "impiagare" and "incendere", which belong to poetic or archaic lexicon are not recognized. When the word cannot be found in the database it is left in the original version, the same happened with word "sen" contracted from "seno" which in Czech may create the impression of a translated word meaning "dream". In the verse "It pierced the archer god", no passive voice was recognized and the expression "nume arciero" was not identified as Eros or Cupido. The idiom "venir meno" was interpreted correctly "faint" even if the verb was contracted. Also, the poetic figure "ciglio nero" was interpreted correctly as "eyes black“ imitating the original word order.

To summarize, it can be stated that the translation of the whole text by Google translator falls short as the relations between the words in a sentence are not translated correctly. Some idiomatic or poetic expressions can be translated but others cannot. Translating the contracted forms from Italian is mostly problematic. Moreover, the translation form Italian to Czech passes through an English database, influencing the final translation in an unacceptable way. The translator is not a suitable tool for specific translations of classical musical texts.

Translating the same quatrain using an Italian-Czech dictionary online [16] word-by-word presents even more difficulties. None of the contracted forms were recognized, the contracted form "sen" is recognized as already translated as "dream", the verbs "impiagare" and "incendere" are not present. Even the past participle "traffitto" is not present and must be searched as a derivation from infinitive form "traffiggere". The orthographically different transcription "arciero" is not present and only the version "arciere" can be found. An idiom such as "venir meno" is not mentioned in the dictionary and neither is the expressions "nume arciero" or the synecdoche "ciglio" which must be interpreted by the student. The form "dal" is not recognized either as a connection of preposition with article. The student must be familiar with it.

In summary, the more frequently used online ItalianCzech dictionary is the least suitable for translations of classical musical texts. There are other online or electronic 
Italian-Czech dictionaries supported by a little wider database but used currently only by $10 \%$ of the students.

Finally, translating the Scarlatti`s quatrain with the help of a traditional paper Italian-Czech dictionary [8] some different results can be observed. None of the contracted forms are found, but the contracted form "sen" cannot be substituted by a Czech word as already translated. The verb "impiagare" is present, only the verb "incendere" is not present but can be related to a present noun, "incendio". The past participle "traffitto" is not present but can be recognized as a derivation of the infinitive form "traffiggere" by the indication related to the template of conjugations. The orthographically different transcription "arciero" is not present but the items "arciera" and "arciere" are. The expression "nume" is provided by the indication of poetic expression so that the student is led to the locution "nume arciero" and the poetic meaning of "ciglio" as "eye" is offered. The idiom "venir meno" is present, as well as the context of each meaning.

The traditional paper Italian-Czech dictionary that offers poetic and sometimes archaic lexicon, including idioms and information about grammatical forms, is ideal for the purpose of translating specific texts such as the scores, even if the searching is very slow and offers a huge number of synonyms compared to the above mentioned dictionaries.

In accordance with the hypothesis that some of the tools are completely unsuitable for such specific translations, it can be stated that the currently used online translator and dictionary are the least recommended tools for translations of musical texts. The traditional paper dictionary is definitely more suitable as a tool for translation of opera scores, even though it presents some disadvantages, too.

In any case, as the results of the presented research demonstrate, the used tool itself is not the main factor influencing the success of a translation. Moreover, the use of any kind of tool is not a natural competence and must be taught, starting with explaining the terms and abbreviations used by a singular dictionary and going through the items' composition, arriving at the correct choice of synonym.

\section{Conclusions}

The research on teaching translation to opera singers, conducted at the Conservatory of Pilsen, the Czech Republic, covering the twelve years period of 2002 till 2014, and concluded with a questionnaire in September 2014 answered three different questions.

Comparing the teaching processes based on the use of traditional and ICT tools with regard to students' translation abilities, the hypothesis about facilitation represented by the use of modern tools was refuted. The changes adopted in the teaching process (obsolete textbooks and paper dictionaries removed, internet and digital interactive materials introduced), giving preference to communicative teaching methods and eliminating or minimizing the old method based on translation, reduced students' translating competence. The students provided with traditional paper textbooks and dictionaries without interactive elements and internet connection in the classroom were better able to translate unknown musical texts than students provided with modern interactive didactic materials, internet, mobile applications and online dictionaries or translators.

The necessity of including translating activities in the teaching process has not decreased as opera singers' needs differ completely from those of students studying Italian for other purposes. The necessity of interpreting complex musical texts together with the students' approach to learning and their preferred methods of vocabulary testing indicates that an approach focused on comparison between Italian and the students' mother tongue would be welcomed.

When analyzing the translation process of classical musical texts of various difficulty, it is essential to take into account details such as the low quality of used scores, specific orthography, obsolete grammatical forms, poetic and archaic lexicon, or poetic word order. The results of the questionnaire compared with the analyzed difficulties did not confirm the hypothesis that tools alone influence the success of translating opera scores. More important aspects, such as the translator's competences, were also found to be of importance.

While comparing traditional and ICT tools, the advantages of ICT tools as interactive, attractive or containing audio and video support were found more suitable for a communicative teaching approach than for musical text translation. On the other hand, the advantages of traditional tools - deep grammatical explanation coupled with a series of examples provided by translation, presentation of poetic lexicon, exercises focused on translation and dealing with problems of translation, were found more suitable for teaching translation of musical texts even if time consuming.

Finally, the model experimental comparison made by translating the same Italian quatrain into Czech using three different tools confirmed the hypothesis that some of the currently used tools are completely, or at the very least less, suitable for such a specific task of translation.

Nevertheless, in order to become an autonomous user of any of the examined tools, it is essential to learn how to use any given tool; only the specific language knowledge imparted in the teaching process, coupled with building translating competences, may allow students to pass from word-by-word translation to the real interpretation of sung texts.

All the found results are of significance, not only for students, but especially for the teacher who is not only considered one of the easily available tools for helping students in their translation, but is also assigned the task of taking advantage of ICT tools and combining them with the advantages of traditional tools. For this reason further research is needed.

\section{Acknowledgements}

I would like to acknowledge the Institute of Applied Language Studies of the University of West Bohemia which contributed to the presented research by providing a theoretical background and financial support. I would also like to extend a special thanks to the Conservatory of Pilsen, the Czech Republic, where the research took place.

\section{References}


[1] Diadori, P, Teoria e tecnica della traduzione: strategie, testi e contesti, Le Monnier, Firenze, 2012, 195-210.

[2] Osimo, B, Manuale del traduttore, $3^{\mathrm{a}}$ edizione. Hoepli, Milano, 2011, 164-169.

[3] Eco, U, Dire quasi la stessa cosa. Bompiani, Milano, 2003.

[4] Kronbergerová, M, Italština pro zpěváky I.-III. díl, vlastním nákladem, Praha, 1996.

[5] Kronbergerová, M, Italština pro operni pěvce, Nakladatelství Akademie múzických umění v Praze, Praha, 2009.

[6] Nicolodi, F, Trovato, P (eds.), LesMu: lessico della letteratura musicale italiana 1490-1950, Franco Cesati Editore, Firenze, 2007.

[7] Bahníková, A, Benešová, H, Ehrenbergová, L, Italština, Státní pedagogické nakladatelství, Praha, 1992.

[8] Rosendorfský, J, Česko-italský slovník, 2. vyd. Státní pedagogické nakladatelství, Praha, 1992.
[9] Marin, T, Albano, A, Progetto italiano Juior 1: Corso multimediale per preadolescenti e adolescenti, Edilingua, Roma, 2009.

[10] Marin, T, Albano, A, Progetto italiano Junior 2: Corso multimediale per preadolescenti e adolescenti, Edilingua, Roma, 2009.

[11] Marin, T, Magnelli, S, Progetto italiano nuovo 1: Corso multimediale di lingua e civiltà italiana. Libro dello studente, Edilingua, Roma, 2009.

[12] Marin, T, Magnelli, S, Progetto italiano nuovo 1: Corso multimediale di lingua e civiltà italiana. Quaderno degli esercizi, Edilingua, Roma, 2010.

[13] Salvini, F, Parlar cantando: Canzoni per bambini, Guerra Edizioni, Perugia, 2003.

[14] Trama, G, Canta che ti passa, Alma Edizioni, Firenze, 2001.

[15] https://translate.google.cz/

[16] https://www.seznam.cz/ 